\title{
DISTRIBUCIÓN ESPACIAL DEL VIÑEDO EN LA COMUNIDAD AUTÓNOMADE LA RIOJA: INFLUENCIA DE LA TOPOGRAFÍA Y DE LAS FORMAS DEL RELIEVE
}

\author{
José ARNÁEZ \\ Dpto. de Ciencias Humanas y Sociales. Universidad de La Rioja. \\ Luis ORTIGOSA \\ Dpto. de Ciencias Humanas y Sociales. Universidad de La Rioja. \\ Pura RUIZ-FLAÑO \\ Dpto. de Geografía. Facultad de Filosofía y Letras. \\ Teodoro LASANTA \\ Instituto Pirenaico de Ecología (CSIC).
}

RESUMEN: Mediante técnicas SIG y análisis estadísticos multivariables se estudian los factores que explican la distribución del viñedo en La Rioja, y se identifican áreas homogéneas. Los resultados muestran que la mayor parte del viñedo se localiza entre 400 y $600 \mathrm{~m}$ de altitud, en glacis y terrazas antiguos, sobre areniscas y arcillas, en pendientes con desniveles por debajo del $20 \%$, y en todas las exposiciones, pero con ligero predominio de los viñedos en solana. Por otro lado, se han identificado 5 unidades homogéneas, siendo la pendiente y la exposición las variables con mayor incidencia. Se señala el interés de conocer la distribución espacial del viñedo para su gestión, al condicionar la localización la calidad de la uva y la conservación del suelo.

PALABRAS CLAVE: viñedo, factores topográficos y geomorfológicos, SIG, La Rioja (España).

ABSTRACT: Physical factors of La Rioja vineyard distribution and characterization. In this paper the factors that explain the vineyard distribution in La Rioja are studied using a GIs. Homogeneous areas of vineyard distribution are identified through multivariable statistical analysis. The results show a preferable location in areas between 400 and $600 \mathrm{~m}$ of altitude, on old glacis and terraces, on sandstones and clays, and on inferior slopes to $20 \%$. The exposures, where the vineyards are cultivated, are mainly sunny. Five homogeneous areas are identified based on the slope and the exposure. The importance of the knowledge of the vineyard distribution for its management is emphasized because the distribution factors determine the grape quality and the soil conservation.

KEY WORDS: vineyard, topographic and geomorphologic factors, GIS, La Rioja (Spain).

RÉSUMÉ: Facteurs physiques influant sur la distribution et la caracterisation du vignoble dans la communaute autonome de la rioja. Les facteurs expliquant la distribution du vignoble de La Rioja sont étudiés à l'aide de techniques SIG et d'analyse statistique multivariée. Les résultats montrent que la plupart du vignoble se situe entre 400 et $600 \mathrm{~m}$ d'altitude, sur d'anciens glacis ou d'anciennes terrasses fluviales généralement orientés au Sud, où le substrat dominant est gréseux ou argileux et les pentes inférieures à $20 \%$. 5 zones homogènes ont été identifiées à partir de critères de pente et d'exposition. L'importance de la connaissance de la distribution du vignoble dans une optique de gestion est soulignée, en raison de son influence sur la qualité du raisin ainsi que sur la conservation des sols.

MOTS-CLÉS: vignoble, facteurs topographiques et géomorphologiques, SIG, La Rioja (Espagne).

RESUMO: Através de técnicas SIG (Sistema de Informação Geográfica) e de análises multivariadas estudam-se os factores que explicam a distribuição do vinhedo em La Rioja, e identificam-se áreas homogéneas. Os resultados mostram como a maior parte do vinhedo 
localiza-se entre os 400 e 600 metros de altitude, em esplanadas e terraços sobre um substrato arenoso e argiloso, em vertentes com desníveis inferiores ao $20 \%$, em todas as exposições, mas com certo predomínio dos vinhedos expostos a sul. Além do mais foram identificadas 5 unidades homogénea, sendo a ladeira e a exposição as variáveis com maior influência. É de se notar o interesse pelo conhecimento da distribuição do vinhedo no lugar para a sua gestão, pois a qualidade da uva e a conservação da terra condicionam a sua localização.

PALAVRAS-CHAVES: vinhedo, factores topográficos e geomorfológicos, SIG, La Rioja (Espanha).

\section{INTRODUCCIÓN}

El cultivo del viñedo se identifica a menudo con el clima mediterráneo. Sin embargo, su presencia en los cinco continentes, bajo condiciones ambientales muy contrastadas, demuestra que su área de cultivo supera a la del clima mediterráneo. Basta recordar su cultivo en regiones tan distintas como el semiárido chileno del Norte Chico y las húmedas colinas alemanas del Kaiserstuhl. Y es que Vitis vinifera constituye una planta capaz de sobrevivir y producir en condiciones ambientales muy diversas. En climas de montaña y/o fríos suele ubicarse en laderas solanas y abrigadas para favorecer la maduración de la uva, lejos de los fondos de valle tratando de evitar fenómenos de inversión térmica. Si el problema es el exceso de agua, los viñedos tienden a dispersarse por laderas a sotavento, buscando el efecto de sombra pluviométrica, o por suelos muy arenosos, que faciliten la infiltración del agua hasta capas profundas. Sin embargo, su desarrollo se complica y-sobre todo- la calidad del vino es menor a medida que nos alejamos del mundo mediterráneo, tanto si se penetra en zonas más húmedas, frías y de menor insolación, como cuando la aridez y la iluminación se incrementan (GLADSTONES, 1992).

La calidad del vino está muy influida por diversos factores, entre los que destacan los derivados del vidueño, las prácticas de laboreo y las técnicas de elaboración. Junto a tales factores hay que incluir los vinculados al clima y suelo, íntimamente relacionados con la localización de los viñedos (HUGLIN, 1978; MONTERO ET AL., 1999; VAN GRAAN, 2002). En la actualidad ésta tiene mucho que ver con la producción de uva de elevada calidad, ya que sólo los buenos vinos pueden competir en el mercado; un mercado que progresivamente se hace más global (más de sesenta países producen vino para comercializar) y más competitivo, como consecuencia del descenso del consumo de vino en el mundo (CARBONNEAU Y TONIETTO, 1998). HINNEWINKEL (2002) señala que en 1985 el consumo mundial era de 280 millones de H1., mientras que en 2000 era de 220 millones de Hl.; en los últimos años parece registrarse un ligero aumento hasta alcanzar los 235 millones de Hl.en 2006. Por otro lado, ese mercado mundial demanda cada vez más unos productos fácilmente identificables, ligados al 
terreno y alejados de los considerados vinos industriales, lo que explica la proliferación de denominaciones de origen en los últimos años. En España, por ejemplo, estas denominaciones eran ya 63 en 2005, la mayor parte constituidas en los últimos quince años.

El viñedo exige, pues, unas condiciones ambientales muy precisas (ligadas al clima y suelo) para producir vino de buena calidad y fácilmente identificable por el consumidor experto, lo que limita su cultivo comercial a algunos espacios muy concretos (FABBRI, 2002). En este sentido, se puede afirmar que el viñedo tiene una fuerte componente espacial. Su deslocalización respecto a los mejores enclaves para su cultivo puede repercutir de forma muy acusada en la calidad del vino, con evidentes consecuencias socioeconómicas.

Junto a estos criterios, hay que destacar la especial sensibilidad del viñedo a la erosión por varios motivos, destacando entre ellos su localización en laderas muy pendientes o en determinados suelos proclives a la instalación y desarrollo de procesos erosivos (USÓN, 1998; RAMOS Y MARTÍNEZ CASASNOVAS, 2004; ARNÁEZ ET AL., 2004). De ahí, que resulte muy interesante conocer dónde se localiza el viñedo, tanto por razones económicas como ambientales.

Considerando lo anterior, los objetivos de este trabajo son, en primer lugar, conocer la distribución del viñedo en La Rioja en función de variables topográficas y geomorfológicas y, en segundo lugar, caracterizar áreas o unidades homogéneas. Se trata de aportar información sobre las características físicas del medio en el que se localiza el viñedo de la Comunidad Autónoma de La Rioja. Su delimitación espacial y caracterización es fundamental para interpretar -al menos parcialmente- las condiciones ambientales del Rioja, y para conocer algunas limitaciones: producción y calidad de la uva y conservación del suelo.

\section{2. ÁREA DE ESTUDIO}

El territorio riojano incluye dos unidades fisiográficas contrastadas (FIGURA 1). Al norte, se sitúan las llanuras de la Depresión del Ebro, caracterizadas por una suave topografía y altitudes comprendidas entre 300 y $600 \mathrm{~m}$. En este sector, el relieve se resuelve en varios niveles de glacis y terrazas, que alternan con restos de plataformas estructurales (GONZALO MORENO, 1981). Los glacis están formados por un sustrato rocoso de areniscas y margas terciarias, cubiertos por acumulaciones cuaternarias, donde la presencia de cantos es frecuente, especialmente en los niveles más altos. Las terrazas poseen suelos más profundos y fértiles que los glacis, si bien las más antiguas cuentan con abundantes materiales sueltos. Por otra parte, al sur se ubica la unidad montañosa que forma un conjunto de serranías con altitudes superiores a $\operatorname{los} 2000 \mathrm{~m}$ en el sector occidental (Sierras de la Demanda, Urbión y Cebollera), y entre 1500 y 2000 m en el 
sector centro-oriental (Los Cameros). En esta unidad las pendientes son más pronunciadas y los espacios aptos para la agricultura escasos, por condiciones climáticas, topográficas y edáficas (ARNÁEZ, 1987; LASANTA ET AL., 1989).

El clima de La Rioja se explica por dos factores fundamentales. En primer lugar, por el progresivo alejamiento de las influencias oceánicas de $\mathrm{W}$ a E, lo que facilita el tránsito desde un clima con rasgos atlánticos en el sector occidental (Rioja Alta y Demanda) hacia ambientes cada vez más mediterráneos, con matices de continentalidad, en La Rioja Baja y serranías orientales (RUIZ URRESTARAZU, 1982). La orografía es el segundo factor importante, al crear un fuerte contraste entre los relieves elevados y accidentados de la mitad meridional de la región y los llanos de la Depresión del Ebro en su mitad septentrional. La oposición entre montaña y llanura, y entre ambientes más oceánicos (al W) y más mediterráneos (al E) origina un mosaico de regímenes climáticos. Las áreas más frescas y húmedas corresponden al sector suroccidental de la región (Sierras de la Demanda y Urbión), mientras que las más cálidas y secas se localizan en el sector nororiental (Rioja Baja). Entre ambos extremos aparecen áreas de transición (NÚÑEZ OLIVERA Y MARTÍNEZ ABAIGAR, 1991). La TABLA 1 incluye algunos datos climáticos interesantes en las dos subzonas vitivinícolas en que se divide la Comunidad Autónoma de La Rioja.

Tabla 1. Datos climáticos de La Rioja Alta y Baja

\begin{tabular}{lcc}
\hline \hline & Rioja Alta & Rioja Baja \\
\hline \hline T. media anual $\left({ }^{\circ} \mathrm{C}\right)$ & $9,8-13,2$ & $13,2-13,9$ \\
Precipitación anual (mm) & $440-650$ & $370-430$ \\
Periodo vegetativo (días) & $190-233$ & $228-237$ \\
Integral heliotérmica (I. de Branas) & $2,9-5,0$ & $4,8-6,1$ \\
\hline \hline
\end{tabular}

FUENTE: TOLOSA y GONZÁLEZ LARREINA (1994)

En La Rioja Alta la influencia mediterránea es menor que en La Rioja Baja. Las precipitaciones alcanzan su máximo en primavera e invierno. El balance hídrico es favorable y pocos los meses con déficit de agua. Las temperaturas son suaves, con amplitud térmica moderada. En La Rioja Baja, las precipitaciones no alcanzan los $400 \mathrm{~mm}$ en la mayor parte de los observatorios, registrándose los máximos en otoño y primavera (FIGURA 2). Las temperaturas son más elevadas, con mayor oscilación térmica que en La Rioja Alta, mostrando un carácter más continental (FIGURA 3). El déficit hídrico y la evapotranspiración potencial alcanzan valores elevados. La integral heliotérmica, expresada mediante el Índice de Branas, muestra valores más altos en La Rioja Baja que en la Alta, fruto del mayor grado de insolación (TABLA 1). Hay que recordar que la vid precisa un valor superior a 2,6, y que los valores óptimos se sitúan entre 4 y 
5. Como valores comparativos se puede señalar que La Rioja Alavesa tiene un valor de 5 y Burdeos de 4 (FERNÁNDEZ, 1985). Una ampliación de las condiciones climáticas del viñedo riojano puede consultarse en ANDRADES RODRÍGUEZ (1991).

De cara al desarrollo de la vid y de la calidad del vino, los suelos de La Rioja pueden clasificarse en tres grandes grupos: suelos arcillo-calcáreos, arcilloferrosos y aluviales (RUIZ HERNÁNDEZ, 1988 y 2001) (FIGURA 4). Los primeros favorecen los vinos de "cuerpo", los segundos los de "medio cuerpo" y los terceros los vinos "ligeros". Los suelos arcillo-calcáreos se desarrollan sobre margas y arcillas del Neógeno-Mioceno. Suelen coincidir con calcisoles háplicos o cambisoles calcáricos, caracterizados por un contenido en caliza superior al $25 \%$, pobres en materia orgánica, con escasa acumulación de arcilla en el horizonte $\mathrm{B}$ e inferiores, y bajo los que aparece una roca margosa que permite la fácil penetración de las raíces. Su coloración es amarilla. Son suelos poco fértiles, bien drenados y muy favorables para el cultivo del viñedo. Los arcilloferrosos (calcisoles pétricos o regosoles calcáricos) se forman sobre areniscas, limonitas, arcillas y margas. Presentan contenidos inferiores al $25 \%$ en caliza y elevada proporción de arcillas, dando lugar a suelos de colores muy rojizos, lo que puede perjudicar la calidad del vino. Los suelos aluviales (fluvisoles) son los más fértiles, pero los menos apropiados para la calidad del vino, ya que su planitud favorece la acumulación de humedad edáfica.

Los suelos arcillo-calcáreos dominan en La Rioja Alta, con extensas manchas en Haro, Briones, San Vicente de La Sonsierra, San Asensio, Cenicero y Fuenmayor. Los suelos arcillo-ferrosos ocupan amplios espacios en La Rioja Baja, especialmente en el tramo bajo del Leza, en los Valles del Jubera y de Ocón, en Ausejo y Tudelilla, en Quel, Autol y Alfaro. Los suelos aluviales se extienden paralelos y próximos a los ríos (CSIC, 1970; MACHIN, 1994).

\section{FUENTES DE INFORMACIÓN Y MÉTODOS}

El documento base e inicial del trabajo fue la cartografía digitalizada de la superficie de viñedo cedida por la Consejería de Agricultura, Ganadería y Desarrollo Rural del Gobierno de La Rioja. Dicha cartografía se elaboró a partir del vuelo de fotografía aérea de 1999, en el marco del proyecto INDO (SIGOLEICO), para delimitar la superficie de olivar y viñedo. La segunda fuente de información fue el Mapa Digital del Terreno (MDT) del Gobierno de La Rioja (equidistancia de curvas de nivel de $5 \mathrm{~m}$ ). Del MDT se obtuvieron los mapas de altitud, pendiente, exposición e insolación.

Se utilizaron también los mapas geológicos de La Rioja Alta, hojas de Casalarreina (169), Haro (170), Santo Domingo de la Calzada (202), Nájera (203) y 
Logroño (204) elaborados por el Instituto Geológico y Geominero de España, y los geomorfológicos de las mismas hojas elaborados por Julián ET AL. (1992), todos ellos a escala 1: 50.000. Los mapas se escanearon y se importaron a un programa gráfico raster (Adobe Photoshop). No se utilizaron mapas de suelos porque sólo se dispone de cartografía a 1:250.000, de escaso detalle, pues, para su implementación en un SIG preparado para superponer capas de información a escala 1:50.000. Terminada esta fase, se trasladaron los ficheros gráficos al Sistema de Información Geográfica IDRISI para su georreferenciación en coordenadas UTM (Huso 30, datum WGS84). Dos retos tuvieron que afrontarse antes de disponer de información útil para este trabajo: la reducción del número de variables y la homogeneización de la información que presentaban los distintos mapas litológicos, ya que se observaron diferencias en las interpretaciones de las unidades geológicas. Se trataron de solucionar consultando otras fuentes cartográficas, bibliográficas y la foto aérea.

Tabla 2. Categorías de las variables litológicas y geomorfológicas.

\begin{tabular}{cll}
\hline \hline Categorías & \multicolumn{1}{c}{ Rocas } & \multicolumn{1}{c}{ Formas de relieve } \\
\hline \hline 1 & Margas y yesos & Escarpes y laderas \\
\hline \hline 3 & $\begin{array}{l}\text { Conglomerados, arenas conglo- } \\
\text { meráticas y calizas }\end{array}$ & $\begin{array}{l}\text { Terrazas fluviales altas (niveles 6 } \\
\text { a 12), medias (niveles 4 a 5) y } \\
\text { bajas (niveles 2 a 3). }\end{array}$ \\
\hline \hline 3 & Areniscas, arcillas y limos & $\begin{array}{l}\text { Glacis: altos (niveles 6 a 12), } \\
\text { medios (niveles 4 a 5) y bajos } \\
\text { (niveles 2 a 3). }\end{array}$ \\
\hline \hline & $\begin{array}{l}\text { Materiales cuaternarios pleistoce- } \\
\text { nos: gravas, arenas, limos y arci- }\end{array}$ & $\begin{array}{l}\text { Nivel 1 de glacis y terrazas, le- } \\
\text { chos de inundación actuales, va- } \\
\text { lles de fondo plano y abanicos } \\
\text { aluviales. }\end{array}$ \\
\hline \hline & $\begin{array}{l}\text { llas } \\
\text { nateriales cuaternarios holoce- } \\
\text { llas, generalmente sueltos }\end{array}$ \\
\hline
\end{tabular}

Las 17 categorías litológicas incluidas en los mapas iniciales se agruparon en 5 y las 25 de los mapas geomorfológicos en 4 (TABLA 2).

Para el tratamiento estadístico de los datos se emplearon los módulos del programa SPSS. Para ello se exportaron a ficheros matriciales (ASCII) las imágenes del SIG, con el fin de que la cartografía pudiera ser tratada como variables en la aplicación de técnicas multivariantes. Se utilizaron dos procedimientos analíticos: métodos descriptivos de distribución de variables y casos, y análisis multifactorial para la clasificación final de unidades homogéneas; en concreto, se realizaron análisis de conglomerados y discriminantes. La distinta tipología 
de las variables (cualitativas y cuantitativas) obligó a un tratamiento previo, tanto de las propias variables como de los casos incorporados. Las variables se organizaron en categorías y los casos en datos binarios (ausencia-presencia).

\section{RESULTADOS}

\subsection{La distribución espacial del viñedo en La Rioja}

La Figura 5 muestra el mapa del viñedo en La Rioja. Se observa que la práctica totalidad de las viñas se localizan en el sector de la Depresión, mientras que no aparece ninguna mancha de viña en la parte meridional, en el tramo riojano del Sistema Ibérico. Esta concentración del viñedo en el llano difiere algo respecto a la localización tradicional, cuando el viñedo cumplía más una función de autoconsumo que comercial. La consulta del Catastro del Marqués de la Ensenada permite comprobar la existencia de viñedos en la mayor parte de los pueblos serranos, a veces cultivados casi en el límite ecológico de Vitis vinifera. Aún en los años cincuenta el viñedo aparecía en muchos municipios serranos, aprovechando microclimas con una integral térmica elevada (barrancos encajados y laderas soleadas o a sotavento), como puso de manifiesto MANZANARES (1988).

Con la sustitución de la orientación de autoconsumo por la comercial, el viñedo se ha ido concentrando en los espacios más favorables para conjugar producción y calidad. En la FIGURA 5 resalta la dispersión de las manchas de viñedo por la mayor parte de las tierras de la Depresión, si bien muestra una mayor concentración en el Bajo Najerilla y Bajo Cidacos, donde en algunos municipios alcanza casi la categoría de monocultivo. En 2002, según información del Consejo Regulador de la Denominación de Origen Calificada Rioja, el viñedo cubría 1372 ha en Aldeanueva de Ebro, 3406 ha en Alfaro, 1143 ha en Ausejo, 1060 ha en Autol, 1182 ha en Briones, 1920 ha en Cenicero, 1575 ha en Fuenmayor, 985 ha en Haro, 1234 ha en Huércanos, 1002 ha en Logroño, 1089 ha en Nájera, 1017 ha en Navarrete, 1716 ha en San Asensio y 1733 en San Vicente de la Sonsierra. Los 14 municipios señalados cubrían 20434 ha, el 53\% del viñedo total de La Rioja. Otros 10 municipios cultivan superficies entre 500 y 1000 ha.

La superficie de viñedo se ha incrementado en La Rioja durante las dos últimas décadas, como consecuencia del buen comportamiento del mercado, lo que ha hecho que la viña sea uno de los cultivos más rentables (LASANTA, 1999). En 1983 la superficie cultivada ascendía a 27395 ha, mientras que en 2002 alcanzaba 38671 ha. Dicho incremento ha tenido lugar en los municipios que ya cultivaban viña en 1983 sin que se hayan añadido otros entre ambas fechas. Más bien ha ocurrido lo contrario, ya que con posterioridad a 1983 hay que re- 
gistrar la desaparición de las últimas viñas en Ezcaray, Almarza de Cameros y Villaverde de Rioja. Las mayores ampliaciones de viñedo han tenido lugar en los municipios más vitícolas; así los 14 municipios con mayor superficie en la actualidad (20434 ha en conjunto) tenían 14385 ha en 1983, lo que supone un incremento del $42 \%$ en 20 años. Los aumentos han sido también significativos en municipios de la Rioja Baja, como Calahorra (de 192 ha a 585 ha), Quel (de 254 ha a 528 ha), Murillo (de 348 ha a 704 ha) y Ocón (de 305 ha a 499 ha), por poner algunos ejemplos. Las ampliaciones en la Rioja Alta han sido mucho más modestas, quizás porque el viñedo ocupaba ya los enclaves apropiados.

\subsection{Distribución del viñedo en función de variables físicas}

Las FIGURAS 6, 7 y 8 muestran la distribución del viñedo en función de las variables topográficas. E1 $73 \%$ del viñedo se localiza en altitudes comprendidas entre 400 y 600 m, dentro pues de las tierras de la Depresión del Ebro. La presencia del viñedo se reduce considerablemente en la franja altitudinal de los 600-700 m, siendo un cultivo casi testimonial por encima de los $700 \mathrm{~m}$.

Figura 6. Distribución del viñedo en La Rioja por altitudes

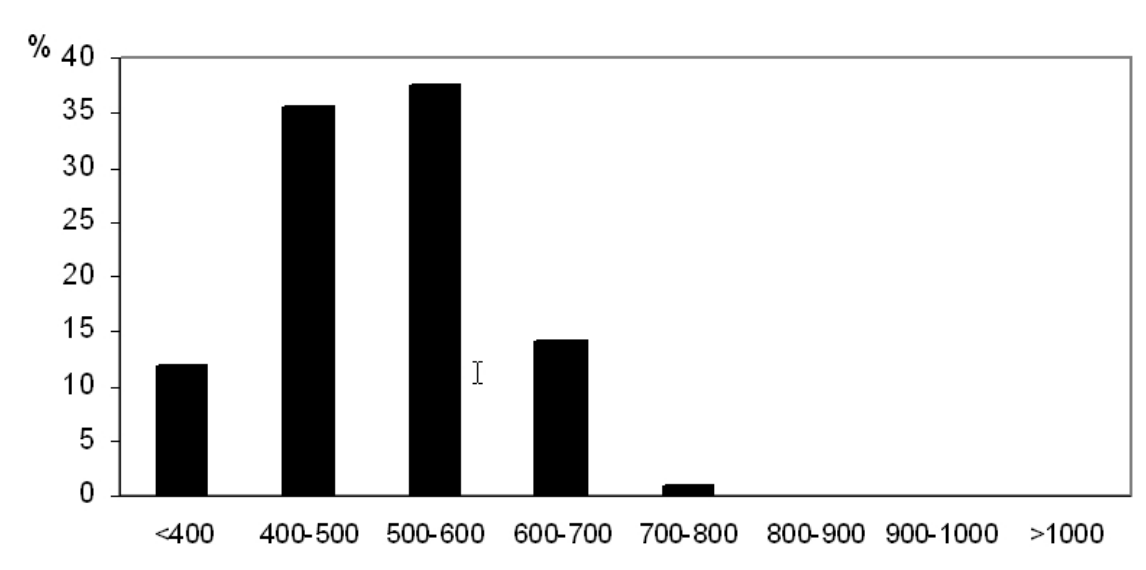

La exposición meridional es la preferente ( $42,2 \%$ del total). La exposición septentrional ocupa el segundo lugar, con el $25,3 \%$. Puede extrañar que la cuarta parte de los viñedos riojanos se localicen en una exposición que, en principio, puede considerarse poco apropiada; ello se explica porque la mayor parte de los glacis se desarrollan en La Rioja de S a N (de la Cordillera Ibérica hacia el centro de la Depresión). La orientación al Norte no implica necesariamente una exposición umbría, ya que al ser un relieve suave, ligeramente inclinado, constituye un espacio abierto. Más interesante resulta constatar que los viñedos orienta- 
dos al $\mathrm{W}$ son muy pocos (el 11,3\% de la superficie total), al huir de los vientos y frentes fríos del Oeste y Noroeste. Mirando al Este se localiza el 21,2\% del viñedo, una exposición que resulta interesante por estar al abrigo de los vientos del Oeste y por recoger directamente el sol de la mañana.

Figura 7. Distribución del viñedo en La Rioja por exposiciones

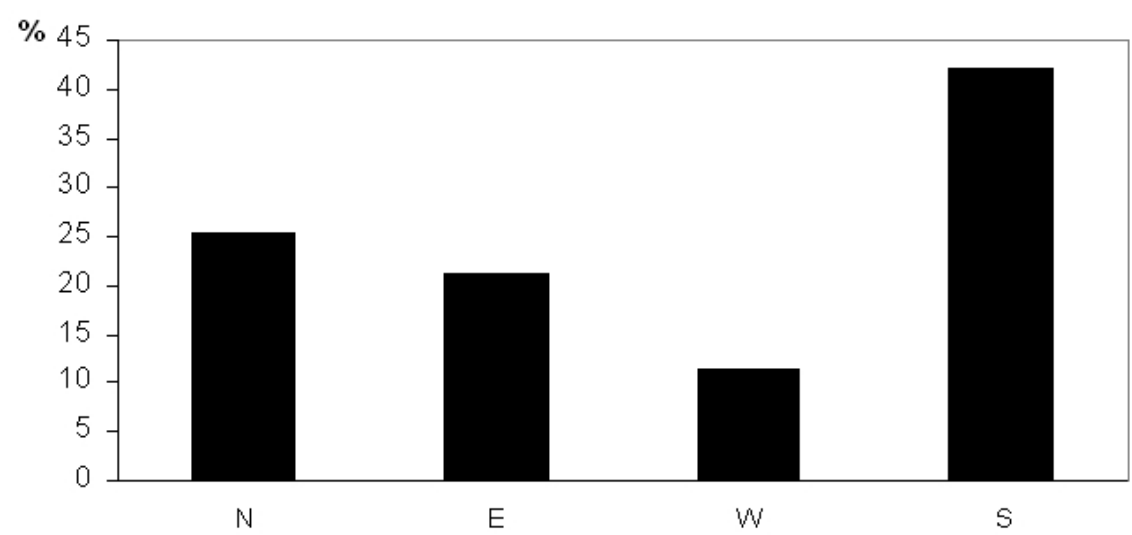

Figura 8. Distribución del viñedo en La Rioja por pendientes

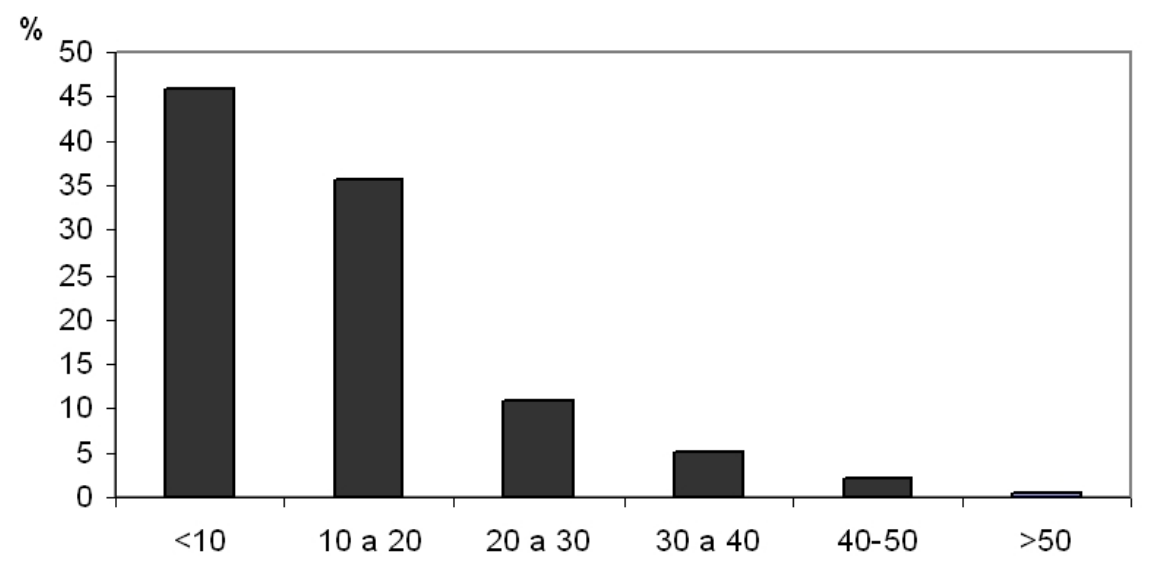

La distribución por pendientes muestra claramente que el viñedo es un cultivo de laderas, e incluso en ocasiones de laderas poco aconsejables para el cultivo, por el grave riesgo de erosión que encierran y por las dificultades que pueden 
plantear para el laboreo con maquinaria agrícola. Por encima del $20 \%$ de pendiente -el umbral considerado máximo para labrar un campo (SCHWING, 1979; TROPEANO, 1983) - se sitúa el 18,7\% del viñedo riojano. En laderas del 10 al $20 \%$ se localiza el 35,6\% del viñedo, superando un desnivel en el que fácilmente pueden activarse escorrentías con gran capacidad erosiva. Sólo el 45,7\% se encuentra por debajo del $10 \%$, en laderas que podemos considerar adecuadas para conjugar producción de calidad y conservación del suelo.

La localización precisa en función del roquedo y las formas de relieve sólo se realizó para la subzona Rioja Alta. La FIGURA 9 refleja la distribución del viñedo en función de los tipos de roca. Las areniscas y arcillas del Terciario son el sustrato preferido por los viticultores (57,3\% de la superficie total). En segundo lugar aparecen los materiales pleistocenos (gravas, arenas y arcillas) con el $31,6 \%$. El resto de litologías cuentan con muy escasa representación.

Figura 9. Distribución del viñedo en La Rioja por litologías

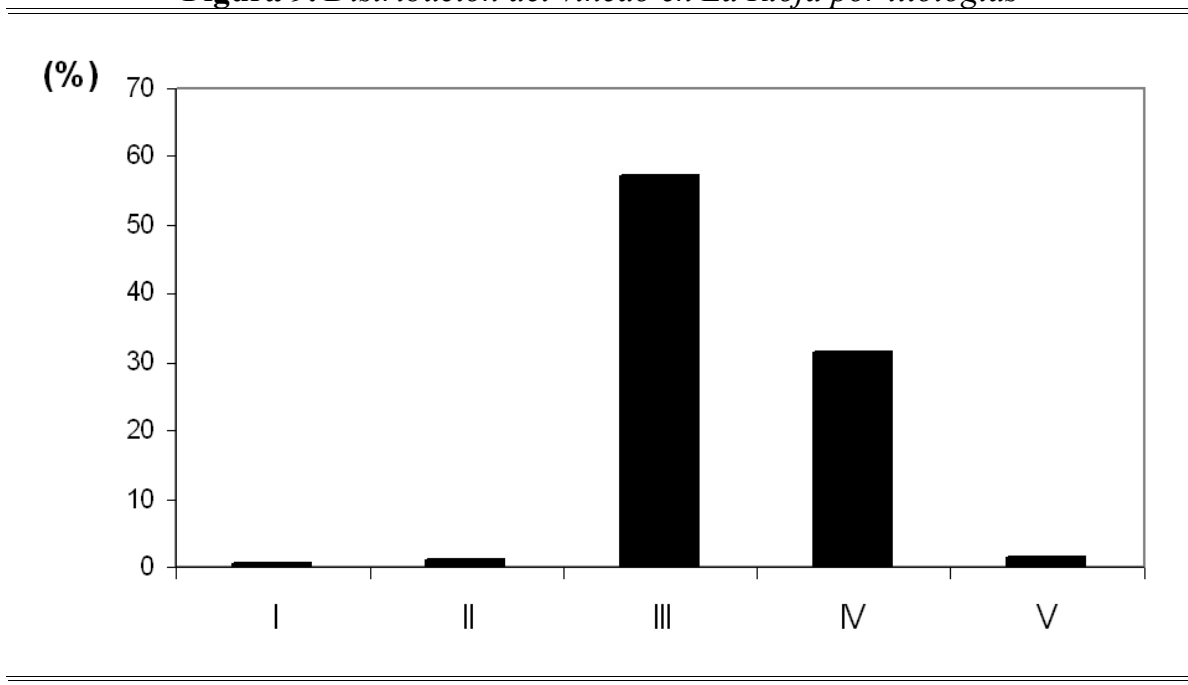

I: Margas/yesos; II: Conglomerados/calizas; III: Areniscas/arcillas; IV: Materiales pleistocenos (gravas, arenas, limos y arcillas); V: Materiales holocenos (gravas, arenas, limos y arcillas)

La FIGURA 10 hace referencia a la localización del viñedo por formas de relieve. Lo más destacable es la fuerte presencia del viñedo en glacis $(41,4 \%)$ y terrazas altas $(22,2 \%)$. Como era esperable, los materiales aluviales del Holoceno (conos aluviales y terrazas recientes) no son áreas preferentes de localización del viñedo, tanto por la competencia que le hacen los cultivos de regadío como por ser áreas menos aptas para el vino de calidad que los niveles de acumula- 
ción antiguos, porque la mayor fertilidad de los suelos incrementa el follaje, lo que resulta perjudicial para la fotosíntesis y la calidad de la uva (REYNIER, 2002). Los escarpes y laderas pronunciadas ocupan el $22,6 \%$ del viñedo, una proporción muy elevada si tenemos en cuenta la amenaza de pérdida de suelo que se ciñe sobre estas laderas.

Figura 10. Distribución del viñedo en La Rioja por formas del relieve

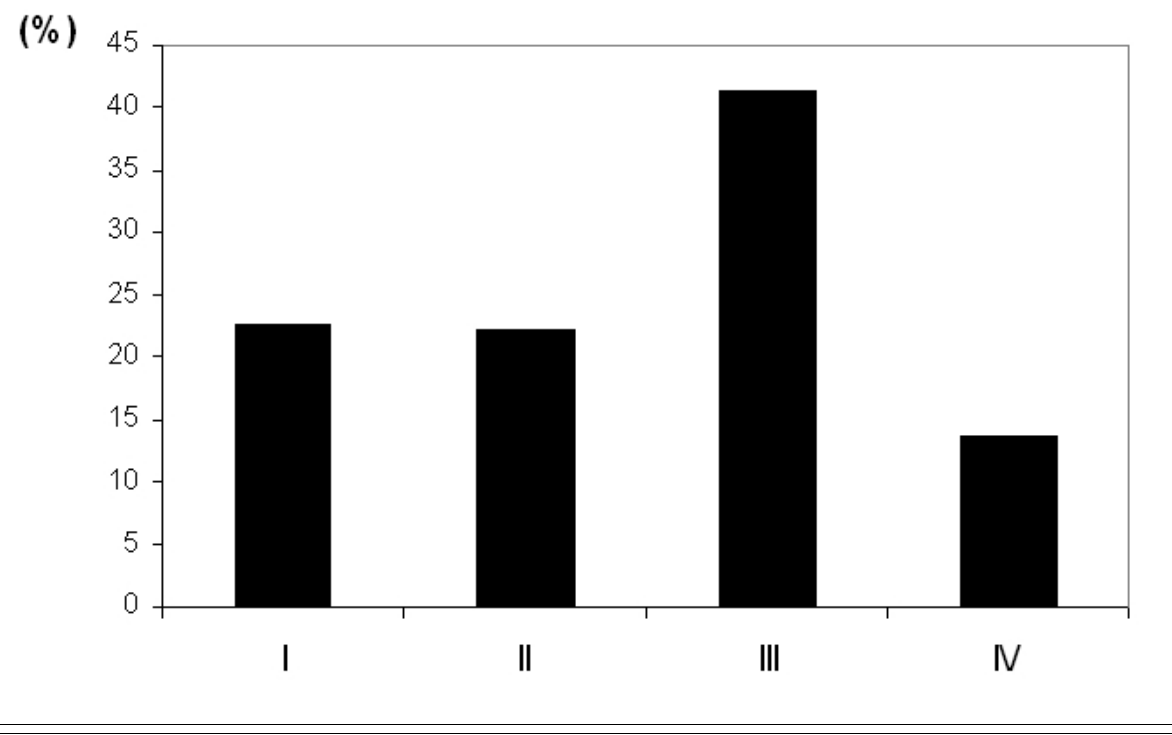

I: Escarpes; II: Terrazas antiguas; III: Glacis antiguos; IV: Aluviales recientes

\subsection{Unidades homogéneas topogeomorfológicas.}

Una vez localizado el viñedo de La Rioja se procedió a la identificación de unidades homogéneas, en función de las siguientes variables: topografía (altitud, exposición y pendiente), mapa de insolación, litología y formas de relieve. Con ello se pretende caracterizar el viñedo desde una perspectiva física, lo que tiene indudable interés de cara, por un lado, a posteriores estudios de mayor detalle (gestión-conservación y análisis experimentales hidromorfológicos, por ejemplo) y, por otro lado, para cartografiar áreas homogéneas en función de su riesgo de erosión.

El dendograma del análisis de conglomerado jerárquico (Cluster) clasificó 5 unidades territoriales, según criterios topogeomorfológicas, cuya importancia con relación a la superficie total queda reflejada en la TABLA 6. Destaca la pre- 
sencia de la unidad 4 ( $41 \%$ de la superficie del viñedo), seguida de la $3(30 \%)$, y a mucha distancia la $2(14 \%)$ y la $1(13 \%)$. La unidad 5 sólo representa el $2 \%$.

Figura 11. Posición que ocupan los centroides de las 5 unidades según las funciones 1 y 2 del análisis discriminante

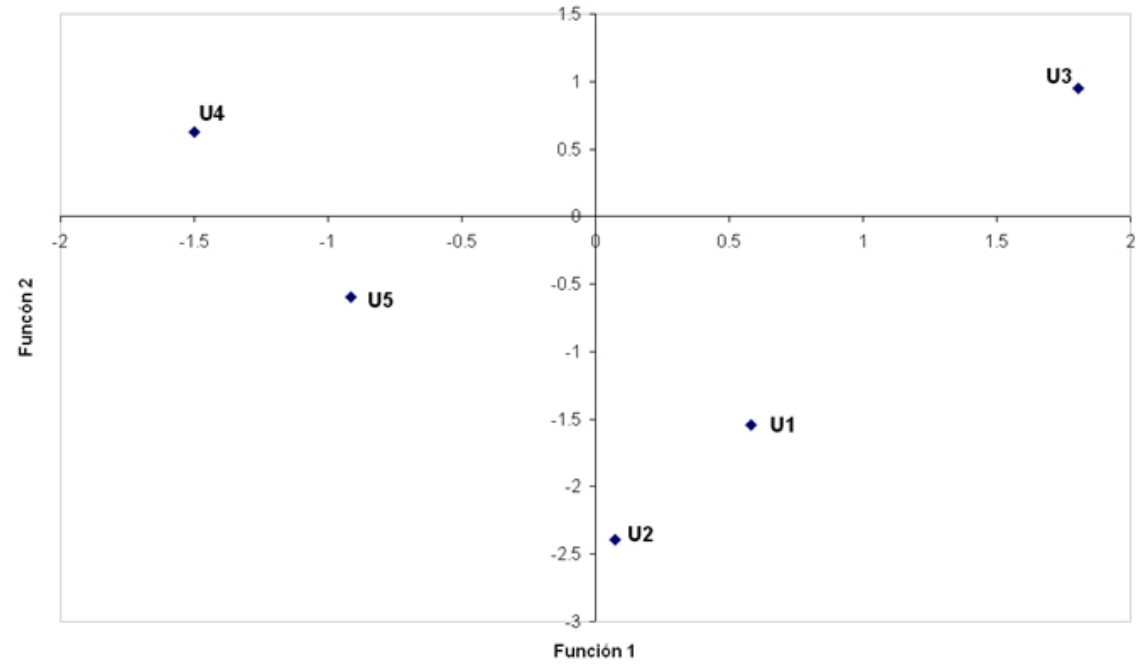

Para conocer las características de estas unidades y determinar los factores que mejor las definen se realizó un análisis multivariable discriminante. En la matriz del análisis discriminante (TABLA 3), la primera función, que explica el $44,1 \%$ de la varianza, hace referencia a las variables geomorfología y exposición y, según la FIGURA 11, discrimina especialmente la unidad 3 con relación a la 4 y 5. La unidad 3 representa antiguas terrazas con orientación Norte. Las unidades 4 y 5 se localizan en glacis antiguos, exposiciones solanas y materiales terciarios de arenas y arcillas. La segunda función, que explica el $34 \%$ de la varianza, contrapone las unidades 1 y 2 con la 3 y 4 (FIGURA 11). Esta función se apoya en los factores topográficos, especialmente en la insolación y pendiente. Las unidades 1 y 2 son viñedos con poca insolación y localizados en pendientes entre 5 y $12^{\circ}$. Las unidades 3 y 4 corresponden a viñedos con insolación media y pendiente inferior a $5^{\circ}$.

La TABLA 4 resume las características de las 5 unidades homogéneas identificadas en los viñedos de La Rioja. De las variables consideradas son la pendiente y la exposición las que tienen un papel más destacado en la diferenciación de unidades, una vez que la mayor parte del viñedo de La Rioja muestra una clara 
tendencia a localizarse en unos espacios muy concretos: terrazas y glacis antiguos, sustrato de areniscas y arcillas, altitudes entre 400 y $600 \mathrm{~m}$.

Tabla 3. Matriz de estructura del análisis discriminante* (Correlaciones entre las variables discriminantes y las funciones discriminantes canónicas tipificadas)

\begin{tabular}{lrr}
\hline Variables & Función 1 & Función 2 \\
\hline Gravas, arenas,.. del Pleistoceno & 0,438 & \\
Areniscas y arcillas & $-0,401$ & \\
Terrazas-(niveles altos) & 0,385 & \\
Exposición Norte & 0,370 & \\
Exposición Sur & $-0,370$ & \\
Glacis (niveles altos) & $-0,197$ & \\
Insolación escasa & & \\
Insolación moderada & & $-0,701$ \\
Pendiente de 5-12 & & 0,556 \\
Pendiente de 2-5 & & $-0,391$ \\
Pendiente $<2^{\circ}$ & & 0,271 \\
Altitud de 400-500 m & & 0,182 \\
\hline
\end{tabular}

* Sólo se han incluido las mayores correlaciones absolutas

Tabla 4. Síntesis de los rasgos más significativos de las unidades homogéneas del viñedo*

\begin{tabular}{|c|c|c|c|c|c|}
\hline Unidad & 1 & 2 & 3 & 4 & 5 \\
\hline $\begin{array}{l}\text { Superf. (\% del } \\
\text { total) }\end{array}$ & 13 & 14 & 30 & 41 & 2 \\
\hline Altitud (m) & 519 & 552 & 518 & 525 & 550 \\
\hline Pendiente $\left({ }^{\circ}\right)$ & 6,0 & 7,4 & 1,9 & 4,2 & 13,1 \\
\hline Insolación** & 44,0 & 44,3 & 48,5 & 51,8 & 63,8 \\
\hline Exposición & $\begin{array}{l}\text { Norte } \\
75.6 \%\end{array}$ & $\begin{array}{l}\text { Norte } \\
81.6 \%\end{array}$ & $\begin{array}{l}\text { Norte } \\
58.7 \%\end{array}$ & $\begin{array}{l}\text { Sur } \\
85,2 \%\end{array}$ & $\begin{array}{l}\text { Sur } \\
99,5 \%\end{array}$ \\
\hline Litología & $\begin{array}{c}\text { Areniscas/ } \\
\text { arcillas } \\
47,1 \%\end{array}$ & $\begin{array}{c}\text { Areniscas/ } \\
\text { arcillas } \\
75,2 \%\end{array}$ & $\begin{array}{l}\text { Gravas, are- } \\
\text { nas y arcillas } \\
\text { del Pleistoce- } \\
\text { no } \\
\quad 71,8 \%\end{array}$ & $\begin{array}{c}\text { Areniscas/ } \\
\text { arcillas } \\
79,7 \%\end{array}$ & $\begin{array}{c}\text { Arenis- } \\
\text { cas/ } \\
\text { arcillas } \\
71,9 \%\end{array}$ \\
\hline Geomorfología & $\begin{array}{c}\text { Terrazas } \\
\text { altas } \\
34,5 \%\end{array}$ & $\begin{array}{c}\text { Escarpes/ } \\
\text { laderas } \\
61,5 \%\end{array}$ & $\begin{array}{c}\text { Terrazas } \\
\text { altas } \\
50,0 \%\end{array}$ & $\begin{array}{c}\text { Glacis } \\
\text { altos } \\
61,7 \%\end{array}$ & $\begin{array}{c}\text { Escarpes/ } \\
\text { laderas } \\
82,2 \%\end{array}$ \\
\hline
\end{tabular}

\footnotetext{
* Se incluyen los valores medios para las variables cuantitativas y la categoría más representativa para las variables cualitativas.

** Se considera baja insolación los valores inferiores a 45; insolación media, valores entre 45 y 55; elevada insolación, valores superiores a 55.
} 
Las unidades 3 y 4 reúnen el $71 \%$ de la superficie de viñedo. Se localizan en laderas de pendiente moderada $\left(1,9^{\circ}\right.$ y $4,2^{\circ}$ de desnivel medio) y solanas (especialmente la 4), con insolación media, sobre terrazas y glacis antiguos, es decir sobre materiales sueltos de gravas, arenas y arcillas. Algunos de los viñedos incluidos en estas unidades se sitúan sobre areniscas y arcillas del Terciario. Las unidades 1 y 2 (que suman el 27\% del viñedo) se localizan en laderas de pendientes medias $\left(6^{\circ}\right.$ y $7,4^{\circ}$, respectivamente), pero suficientemente pronunciadas como para generar procesos de erosión incluso con lluvias moderadas (LASANTA Y SOBRON, 1988). Orientadas al Norte reciben menos insolación que el resto de las unidades. La unidad 2 se encuentra en escarpes y laderas que sirven de contacto a los distintos niveles de glacis y terrazas. La unidad 5 sólo representa el $2 \%$ del viñedo. Se trata de campos situados en niveles de contacto con pendientes pronunciadas $\left(13,1^{\circ}\right.$ de media), de alto riesgo para ser afectadas por procesos de erosión severos. La exposición dominante es la Sur (99,5\%), por lo que son viñedos con elevada insolación, lo que podría explicar la elección de tales parcelas para el cultivo de viñedos.

\section{DISCUSIÓN Y CONCLUSIONES}

Los cultivos son organizados en el espacio de acuerdo con una compleja interacción de factores ambientales (suelos, clima, topografía, relieve,...) y humanos, teniendo especial relevancia la dinámica del mercado y la disponibilidad de mano de obra / medios técnicos, ya que explican los procesos de contracción y expansión. La vid se acopla perfectamente a dicho esquema. La vid está presente en el paisaje agrario y en la economía riojana desde la Alta Edad Media (HuETZ DE LEMPS, 1967). Desde entonces el viñedo fue ampliando su superficie de forma casi constante hasta alcanzar 47.537 ha en la provincia de Logroño (actual Comunidad Autónoma de La Rioja) en las décadas anteriores a la crisis de la filoxera, que supuso la destrucción de 36.000 ha. Desde inicios del siglo XX y hasta mediados de los ochenta, el viñedo crece de forma lenta, sucediéndose periodos expansivos, coincidentes con precios altos de la uva, con otros de "arrinconamiento" del viñedo. Así, en 1950 se cultivaban 43.419 ha; en 1983, 27.395 ha; y en 2002, 38.671 ha.

La vid ha ido acomodándose a lo largo del tiempo hasta encontrar sus ecotopos más favorables para compatibilizar producción con calidad. De ahí que en la actualidad se encuentre preferentemente en terrazas y glacis altos, donde dominan suelos pardo calizos, con materiales sueltos, pedregosos, relativamente profundos y con un componente calcáreo adecuado; lejos de los fondos de valle, donde las nieblas y las heladas pueden dificultar el desarrollo de los sarmientos y uvas; lejos de los materiales aluviales del Holoceno, con suelos muy fértiles y con frecuencia muy húmedos, lo que favorece el vigor vegetativo de la vid (excesivos tallos y abundancia de hojas), pero no su fructificación. Hay que 
recordar que el aumento de superficie foliar produce una mayor asimilación y acumulación de productos en el grano de uva, que no se transforman en el periodo de maduración, en parte debido a que el excesivo follaje disminuye la exposición al sol (PASCUAL Y CABRERIZO, 1995). El viñedo de calidad busca tierras más bien pobres, sin excesivos nutrientes, lo que le ha llevado a ocupar con frecuencia- antiguos encinares y carrascales. GARCÍA-RUIZ Y ARNÁEZ (1987) lo ponen de manifiesto en Cenicero, uno de los municipios vitícolas por excelencia, donde desde mediados del siglo XVIII se deforestaron encinares para plantar viñedos. MANZANARES (1987) señala que en la Dehesa de Navarrete (situada sobre un glacis Pliocuaternario) los encinares fueron arrancados y el glacis roturado para el cultivo del viñedo.

En este trabajo, utilizando como base el mapa actual de viñedos de La Rioja, se ha comprobado que la totalidad de las viñas se encuentran en el sector de la Depresión del Ebro, alejadas de los municipios cameranos, donde en el siglo XVIII llegaban hasta los $1.000 \mathrm{~m}$ de altitud (Catastro de Ensenada) y de los demandinos (MERINO URRUTIA, 1956). Se ha constatado que el viñedo se localiza en el llano riojano, mayoritariamente entre los 400 y $600 \mathrm{~m}$ de altitud, en niveles de acumulación antiguos y sobre suelos de areniscas y arcillas. A partir del MDT y la aplicación de un SIG se ha comprobado que la pendiente y la exposición son las variables más influyentes para diferenciar unidades homogéneas. En este caso, el papel del clima, determinante a la hora de producir uva de calidad, se introduce a través de las variables topográficas (pendiente y exposición), que originan ambientes locales muy apropiados para el cultivo de la vid. En un trabajo reciente, TONIETTO Y CARBONEAU (2004) estudian las condiciones climáticas de 97 zonas de viñedo distribuidas por 29 países. En los resultados puede constatarse que el Rioja y el Ribera del Duero gozan de las condiciones más apropiadas para producir vino de calidad, sólo compartidas por los viñedos franceses de Montpellier, Carcassonne y Montélimar, los italianos de Rabean y los portugueses de Anadia.

Llama la atención que el 54,3\% de los viñedos se localizan en campos con más del 10\% de desnivel (el 18,7\% de ellos en laderas que superan el 20\%), a pesar de acarrear la pérdida progresiva de suelo fértil, un mayor estrés hídrico para la cepa y la exportación de nutrientes y elementos contaminantes de suelos y aguas de retorno. En este sentido, LE BISSONNAIS ET AL. (2001) señalan que las principales áreas afectadas por riesgo de erosión en Francia coinciden con los espacios ocupados por el viñedo y los cultivos de primavera. A la misma conclusión llegan LISA y FERRERO (2004) en el Piedmont (Piedemonte de los Apeninos, Italia), y MARTíNEZ CASASNOVAS Y SÁNCHEZ BOSCH (2000) para la comarca del Penedés, donde constatan que entre 1950 y 1990 el 12,6\% de las tierras experimenta un balance negativo en la conservación del suelo, como 
consecuencia de la expansión del viñedo y de la mecanización creciente de las labores agrícolas. En la misma comarca, MARTínEZ CASASNOVAS ET AL. (2005) cuantificaron pérdidas de $286 \mathrm{Mg} / \mathrm{ha}^{-1}$ como consecuencia de un evento extraordinario de lluvia (214,6 litros en un día), evaluando los costes económicos de las operaciones necesarias para redistribuir el sedimento/suelo en el campo en el $5 \%$ de los ingresos de los agricultores. El mismo evento implicó el desplazamiento de $108 \mathrm{~kg} / \mathrm{ha}^{-1}$ de N, 108,6 kg/ha-1 de P y $356 \mathrm{~kg} / \mathrm{ha}^{-1}$ de K (RAMOS Y MARTÍNEZ CASASNOVAS, 2004). En viñedos de La Rioja se comprobó que eventos de baja intensidad producen desplazamientos de sedimentos de hasta $10 \mathrm{~kg} / \mathrm{ha}$, con una gran variabilidad en función de los sistemas de laboreo (LASANTA Y SOBRÓN, 1988). La concentración de los flujos de escorrentía en surcos y cárcavas contribuye a incrementar el estrés hídrico de las cepas (MONTERO-RIQUELME y BRASA, 2005) y la contaminación de acuíferos, redes hídricas y suelos aguas abajo, por fungicidas (RIBOLZI ET AL., 2001) y herbicidas (LOUCHART ET AL., 2004).

Mediante un análisis cluster y un discriminante se han identificado cinco unidades homogéneas que responden a condiciones ambientales en parte coincidentes y en parte distintas. La unidad 1, que ocupa el 13\% de la superficie total, corresponde a viñedos en exposiciones al Norte, con pendientes entre 5 y $12^{\circ}$, sobre terrazas antiguas. La unidad 2 (14\% del total) comparte características muy parecidas con el grupo anterior, pero se localizan preferentemente en escarpes y laderas muy pendientes. La unidad 3 (30\% del total) está formada por viñedos sobre terrazas altas pleistocenas, compuestas de gravas, arenas y arcillas compactadas, que se localizan en orientaciones al Norte y a 400-500 m de altitud; con buena insolación y pendientes por debajo de $5^{\circ}$. La unidad 4 es la más extensa ( $41 \%$ de la superficie); se trata de viñedos sobre glacis altos del Pleistoceno, donde dominan las arenas y arcillas, en exposición solana, entre 400 y $500 \mathrm{~m}$ de altitud y pendientes inferiores a $5^{\circ}$. La unidad 5 (2\% de superficie) está formada por viñedos en escarpes y laderas pronunciadas, con materiales terciarios, en exposición solana y pendientes que frecuentemente superan los $12^{\circ}$. Se comprueba, pues, que el viñedo de La Rioja se distribuye por un espacio relativamente heterogéneo, tratando de conjugar las exigencias ambientales, para obtener buenas producciones de uva en cantidad y calidad, con las de los viticultores que buscan enclaves (con frecuencia poco idóneos) para las nuevas plantaciones, en el marco de la fase expansionista en la que está instalado el viñedo de Rioja desde hace más de una década (LASANTA Y PASCUAL BELLIDO, 1999).

Los resultados obtenidos en este trabajo aportan información sobre la distribución espacial del viñedo actualmente. Pueden constituir un punto de partida para llevar a cabo estudios sobre identificación de áreas idóneas para la locali- 
zación del viñedo en función de la calidad del producto final y del mayor o menor riesgo de erosión del suelo, aspectos clave de cara a la gestión futura del viñedo.

\section{AGRADECIMIENTOS}

Este trabajo se ha realizado con el apoyo financiero de los proyectos de investigación: Aplicación de modelos de erosión en laderas cultivadas con viñedos sometidos a precipitaciones intensas: el caso de La Rioja (ANGI 2003/01), financiado por el Gobierno de La Rioja, Comportamiento y modelización espacio-temporal de la transferencia de sedimentos en diferentes usos del suelo: laderas con un uso agrario intensivo (CETSUS) (CGL2007-66644-C04-0), financiado por la Secretaría de Estado de Universidades e Investigación, y Procesos y balances hidrológicos y de sedimentos a diferentes escalas espaciales en ambientes mediterráneos: Efectos de las fluctuaciones climáticas y los cambios de uso del suelo (PROBASE) (CGL2006-116191/HID), financiado por el Plan Nacional I+D, categoría Consolider.

\section{BIBLIOGRAFÍA}

ANDRADES RODRÍGUEZ, A. 1991, Influencias climáticas sobre el proceso de maduración del fruto de Vitis vinifera. Diferenciación varietal. Consejería de Agricultura y Alimentación (Gobierno de La Rioja). Serie Estudios, 20, Logroño.

ARNÁEZ, J. 1987, «Formas y procesos en la evolución de vertientes de la Sierra de la Demanda (Sistema Ibérico)». Cuadernos de Investigación Geográfica, 13, 7-153.

ARnÁEZ, J., Ortigosa, L., LASANTA, T., Ruiz-Flaño, P. Y MAESTRo, M. 2004, «Escorrentía y producción de sedimentos con diferentes intensidades de precipitación en laderas cultivadas con viñedos (La Rioja, España)». En: Riesgos Naturales y Antrópicos en Geomorfología (G. Benito \& A. Díez Herrero, Edrs.). Sociedad Española de Geomorfología y Consejo Superior de Investigaciones Científicas, pp. 267-285, Madrid.

CARBonneaU, A. Y TONIETTO, J. 1998, «La géoviticulture: de la géographie viticole aux évolutions climatiques et technologiques à l'échelle mondiale». Revue Oenol.Tech. vitivin. Oenol., 87: 16-18.

C.S.I.C., 1970, Mapas de suelos de las provincias de Zaragoza, Huesca y Logroño (Escala 1: 250.000). Consejo Superior de Investigaciones Científicas, Madrid.

FABBRI, L. 2002, «Terroir, territoire, réglementation, tecnique... Une reflexión autour de la qualité des vins. Exemple en Languedoc». Sud-Ouest Européen, 14 : 51-60.

FERNÁNDEZ, J.I. 1985, Contribución la estudio de características de los vinos de distintas subzonas de Rioja. Consejería de Agricultura y Alimentación, Serie Estudios, 2, Logroño.

GARCÍA-RUiZ, J.M. y ARNÁEZ, J. 1987, «El medio natural». En: Cenicero histórico. Ayuntamiento de Cenicero - Comunidad histórica de La Rioja, p. 11-56, Logroño.

GladSTONES, J. 1992, Viticultura and environment. Winetitles, 310 pp., Adelaida. 
GonZalo Moreno, A.N. 1981, El relieve de La Rioja. Análisis de Geomorfología Estructural. Instituto de Estudios Riojanos, 2 tomos, Logroño.

HuETZ DE LEMPS, A. 1967, Vignobles et vins du Nord-ouest de l'Espagne. Institut de Géographie, Faculté de Lettres de Bordeaux, 2 Vols, Bordeaux.

HinNEWINKEL, J.C. 2002, «Les vins du Sud-Ouest européen et la mondialisation. Avant-propos». Sud-Ouest Européen, 14, 1-8.

Huglin, P. 1978, «Nouveau mode d'évaluation des possibilités héliothermiques d'un milieu viticole». In: Proceedings of the Symposium International sur l'Ecologie de la Vigne. Ministère de l'Agriculture et de l'Industrie Alimentaire, 89-98 pp., Contanca.

Julián, A., PEÑA, J.L. Y CHUECA, J. 1992, Mapas geomorfológicos a escala 1:50.000 de Casalarreina (Hoja 169), Haro (Hoja, 170), Santo Domingo de la Calzada (Hoja, 202), Nájera (Hoja, 203) y Logroño (Hoja, 204). Instituto de Estudios Riojanos, Logroño. Inéditos.

LASANTA, T. 1999, «Evolución reciente del mercado del Rioja y cambios en el sector vitivinícola». Berceo, 136, 193-214.

LASANTA, T., ARNÁEZ, J., Ruiz FlaÑo, P. Y ORTIGOSA, L. 1989, «Evolución superficial del espacio cultivado en Cameros Viejo (Sistema Ibérico) y su relación con algunos factores geoecológicos». Estudios Geográficos, 197, 553-572.

LASANTA, T. Y PASCUAL BELlido, N., 1999, «Efectos de los usos del suelo en la dinámica reciente del mercado del Rioja». Polígonos, 9: 215-225.

LASANTA, T. Y SOBRÓN, I., 1988, «Influencia de las prácticas de laboreo en la evolución hidromorfológica de suelos cultivados con viñedo». Cuadernos de Investigación Geográfica, 14: 81-97.

Le Bissonnais, Y., Montier, C., Jamagne, M., Daroussin, J. Y King, D. 2001, «Mapping erosion risk for cultivated soil en France». Catena, 46: 207-220.

LisA, L. y FERrERO, A. 2004, «Excursión to Vezzolano Experimental Farm. Excursión»: 10th Internacional Conference of the European Network of Experimental and Research Basins, Turín (Italia).

Louchart, X., Voltz, M., Coulouma, G. Y AndrieuX, P. 2004, «Orzalin fate and transport in runoff water in Mediterranean vineyards». Chemosphere, 57: 921-930.

MACHIN, J. (1994): «Los suelos». En: Geografía de La Rioja. Tomo I: Geografía Física. Caja Rioja: 243-250, Logroño

MANZANARES, C. 1987, «El impacto de las transformaciones del medio rural en la utilización de los bosques: los encinares de La Rioja» Estudios Geográficos, 189, 619637.

MANZANARES, C. 1988, «Influencia de los factores topogeomorfológicos en la distribución y evolución de cultivos en el valle del Ebro riojano». Berceo, 118, 43-51.

Martinez CASASNOVAS, J.A. Y SÁNCHEZ BosCH, I. 2000, «Impact assessment of changes in land use/conservation practices on soil erosion in the Penedés-Anoia vineyard region (NE Spain)». Soil and Tillage Research, 57: 101-106.

Martinez CASASNOVAS, J.A., RAMOS, M.C. Y RIBES-DASI, M. 2005, «On-site of concentrated floor erosion in vineyard fields: some economic implications». Catena, 60: 129-146.

Merino UrRutia, J. 1956, «El retroceso del cultivo de la vid en La Rioja Alta y su límite actual». Berceo, 37, 425-428. 
MonTERO, F.J. Y BRASA, A. 2005, «Land and water use management in vine growing by using geographic information systems in Castilla-La Mancha, Spain». Agricultural Water Management,

Montero, F.J., Meliá, J., Brasa, A. Segarra, D., Cuesta, A. y Lanjeri, S. 1999, «Assessment of wine development according to available water resources by using sensing methods in La Mancha, Spain». Agriculture Water Management, 40: 363375 .

NúÑEZ Olivera, R. Y MARTínez AbAigAR, J. 1991, El clima de La Rioja. Análisis de precipitaciones y temperaturas. Consejería de Agricultura y Alimentación (Gobierno de La Rioja), p. 323, Logroño.

PASCUAL, N. Y CABRERIZO, A. (1995): «Distribución espacial del viñedo de Rioja en relación con los condicionantes ambientales». Berceo, 129, 75-95.

RAMOS, M.C. Y MARTÍNEZ CASASNOVAS, J.A. 2004, «Nutrient losses from a vineyard soil in Northeastern Spain caused by an extraordinary rainfall event». Catena, 55, 79-90.

ReYNIER, A. 2002, Manual de Viticultura. Ediciones Mundi Prensa, p. 497, Madrid.

Ribolzi, O., VAlles, V., GÓMEZ, L. Y VOLTZ, M. 2001, «Speciation and origino f particulate copper in runoff water from a Mediterranean vineyard catchment». Environmental Pollution, 117: 261-271.

Ruiz HernándeZ, M. 1988, «El Vino de Rioja». El Campo, 110, 55-66.

RUIZ HERNÁNDEZ, M. 2001, «El suelo y la cata de vinos». En: El suelo y su trabajo en relación con la calidad de los vinos. Ayuntamiento de Haro: 83-102, Haro.

RUIZ URRESTARAZU, E. 1982, La transición climática del Cantábrico oriental al Valle medio del Ebro. Diputación Provincial de Alava, p. 661, Vitoria.

SCHWING, J.F. 1979, «Cartographie de l'érosion en milieu agricole: méthodes et principaux résultats en fonction des différents substrats et pentes. Exemple du vignoble alsacien». Zeitschrift für Geomorphologie, 23: 199-214.

TOlOSA, L. Y GONZÁLEZ LARRAINA, M. 1994, Vinos y bodegas de Rioja. RT\&A.

TONIETTO, J. Y CARBONNEAU, A. 2004, «A multicriteria climatic classification system for grape-growing worlwide». Agricultural and Forest Meteorology, 24, 81-97.

TROPEANO, D. 1983, «Soil erosion on vineyards in the Tertiary Piedmontese Basin (Northwestern Italy): Studies on experimental areas». In: Rainfall Simulation, Runoff and Soil Erosion. Catena Supplement, 4: 115-127.

Usón, A. 1998, Medidas de control de la erosión en suelos de viña de las comarcas de Anoia-Alt Penedés (Barcelona): Efectividady viabilidad. Tesis Doctoral. Universidad de Lérida, p. 229, Lérida.

VAN GRAAN, C. 2002, The approach followed in the cultivation-vinification of ultrapremium wines in California. Wynboer Technical Guide for Wine Producers, New Zealand. 
Figura 1. Mapa de pendientes de La Rioja

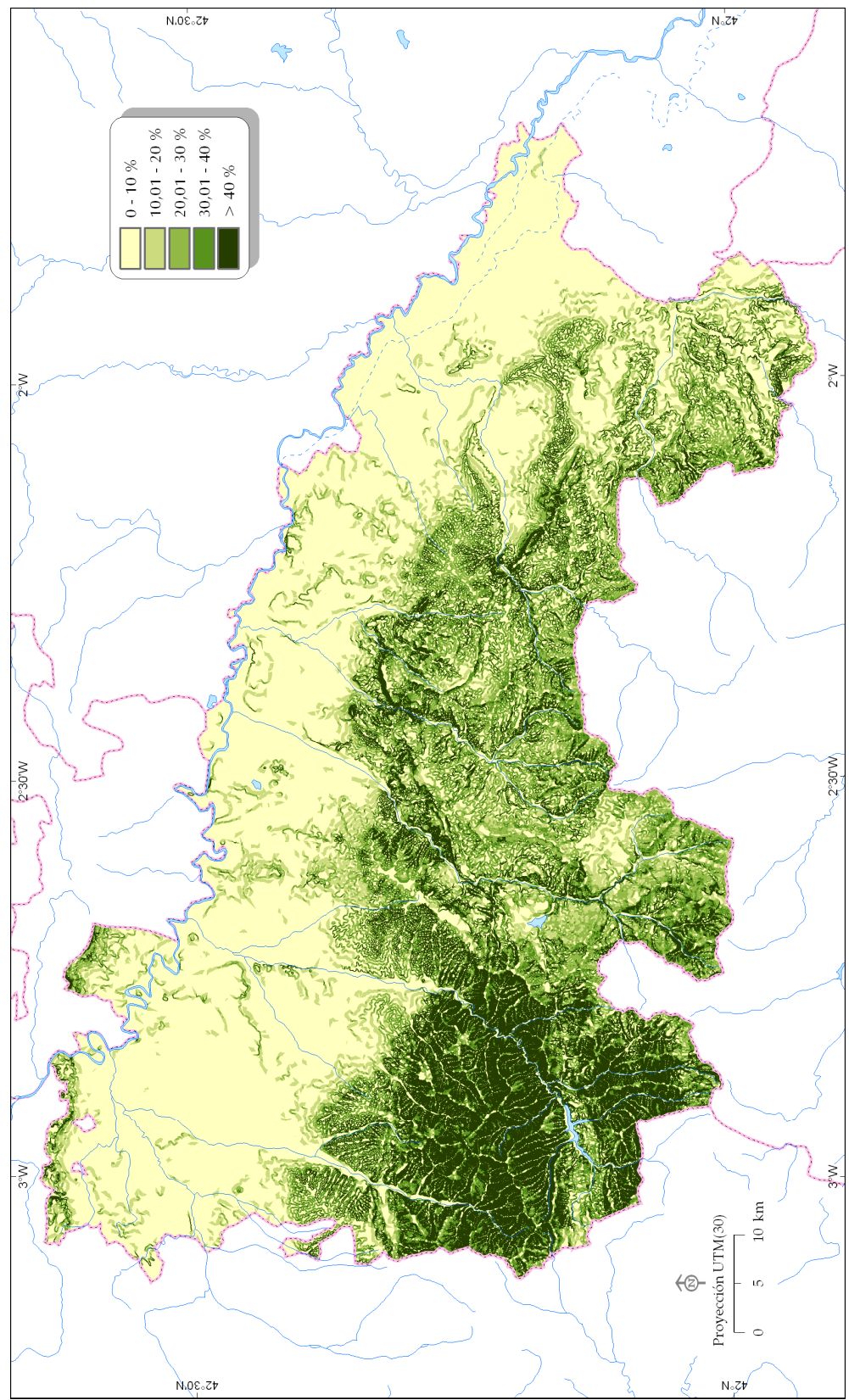


Figura 2. Mapa de precipitaciones totales anuales de La Rioja

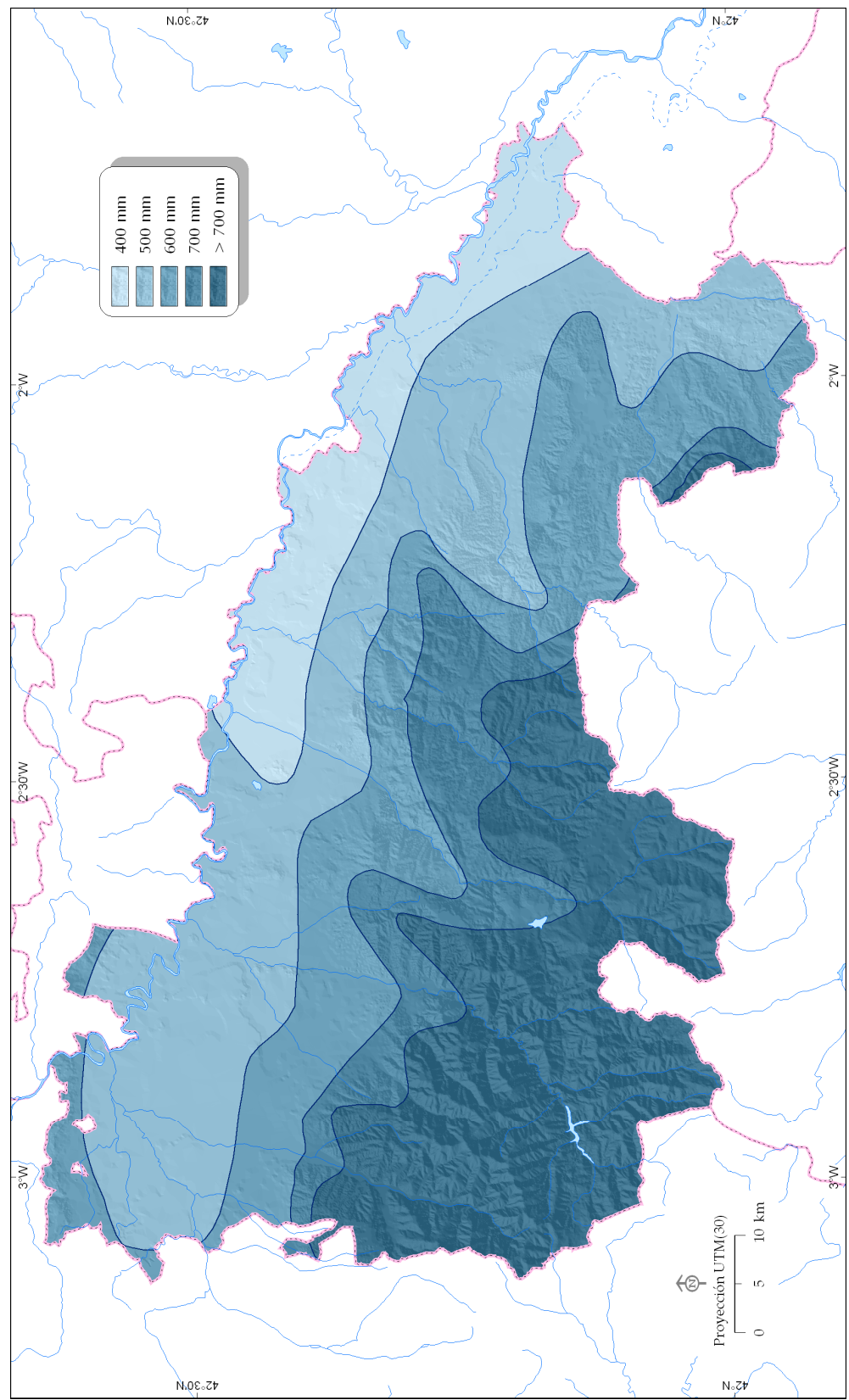


Figura 3. Mapa de temperaturas medias anuales de La Rioja

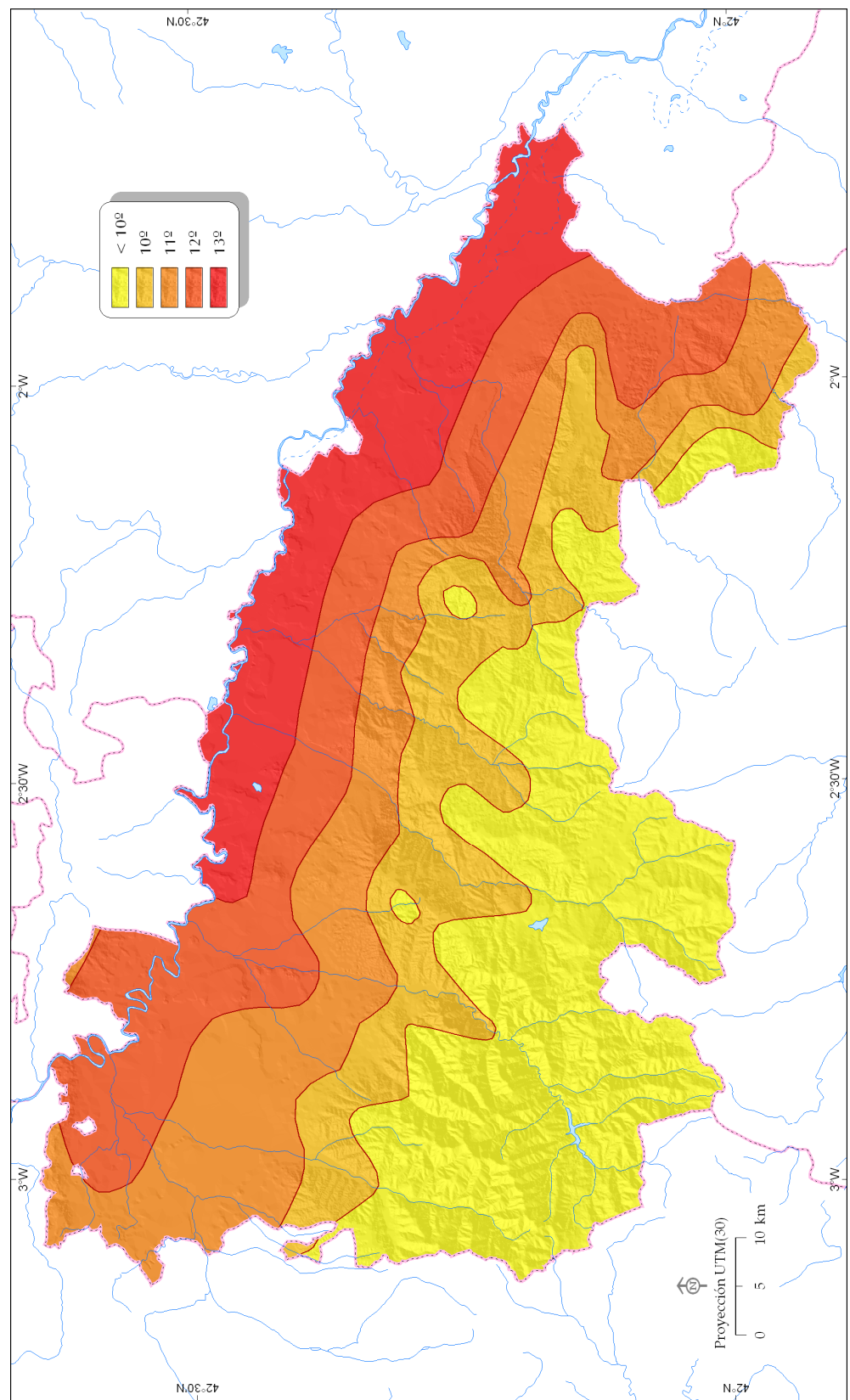

Polígonos. Revista de Geografia, 16 (2006); pp. 11-34 
Figura 4. Mapa de suelos de La Rioja (FUENTE: Machín, 1994)

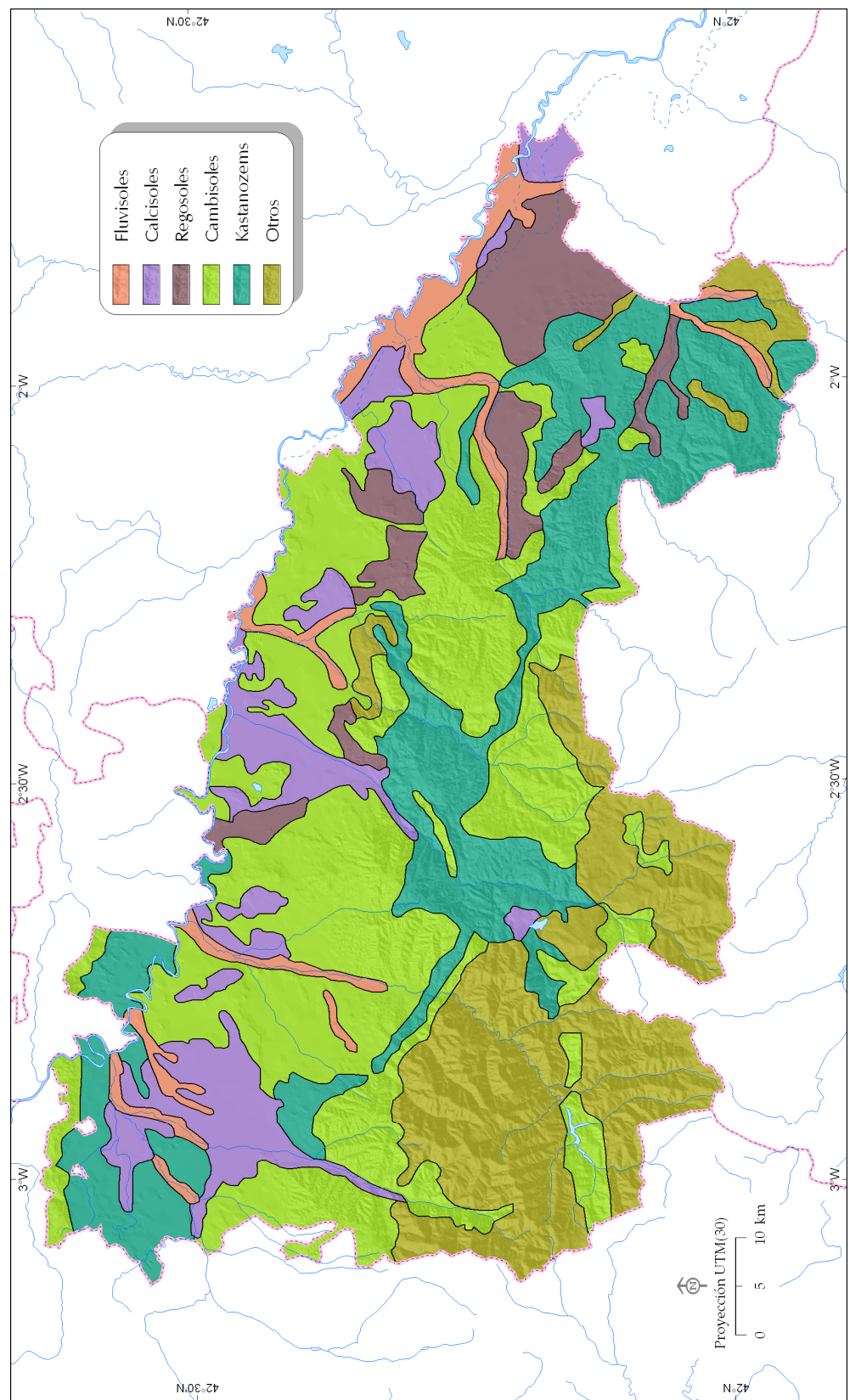


Figura 5. Superficie de viñedo en La Rioja (INDO)

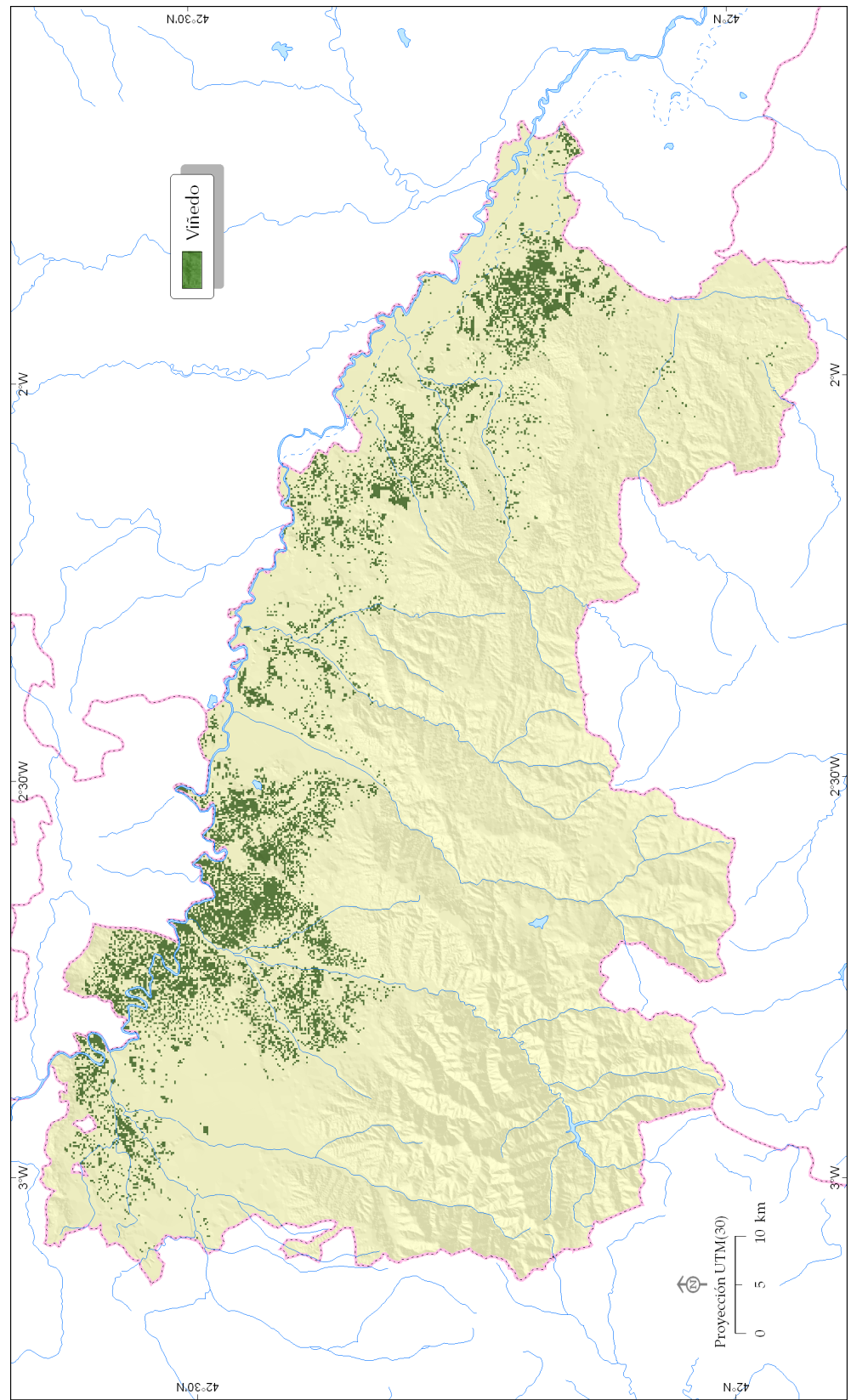

